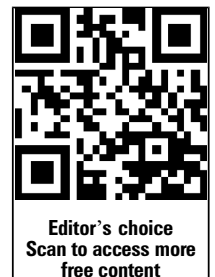

free content

- Additional material is published online only. To view please visit the journal online (http://dx.doi.org/10.1136/ tobaccocontrol-2013-051110).

${ }^{1}$ Global Public Health Unit, School of Social \& Political Science, University of Edinburgh, Edinburgh, Midlothian, UK

${ }^{2}$ UK Centre for Tobacco Control Studies, Centre for Population Health Sciences, University of Edinburgh, Edinburgh, Midlothian, UK ${ }^{3}$ Centre for Population Health Sciences, University of Edinburgh, Edinburgh, Midlothian, UK

\section{Correspondence to} Dr Sarah Hill, Global Public Health Unit, School of Social \& Political Science, University of Edinburgh, 15a George Square, Edinburgh EH8 9LD, UK;

s.e.hill@ed.ac.uk

Received 14 April 2013 Revised 20 August 2013 Accepted 27 August 2013

Published Online First

17 September 2013

\title{
Impact of tobacco control interventions on socioeconomic inequalities in smoking: review of the evidence
}

\author{
Sarah Hill, ${ }^{1}$ Amanda Amos, ${ }^{2}$ David Clifford, ${ }^{3}$ Stephen Platt ${ }^{3}$
}

\begin{abstract}
Objective We updated and expanded a previous systematic literature review examining the impact of tobacco control interventions on socioeconomic inequalities in smoking.
\end{abstract}

Methods We searched the academic literature for reviews and primary research articles published between January 2006 and November 2010 that examined the socioeconomic impact of six tobacco control interventions in adults: that is, price increases, smokefree policies, advertising bans, mass media campaigns, warning labels, smoking cessation support and community-based programmes combining several interventions. We included English-language articles from countries at an advanced stage of the tobacco epidemic that examined the differential impact of tobacco control interventions by socioeconomic status or the effectiveness of interventions among disadvantaged socioeconomic groups. All articles were appraised by two authors and details recorded using a standardised approach. Data from 77 primary studies and seven reviews were synthesised via narrative review.

Results We found strong evidence that increases in tobacco price have a pro-equity effect on socioeconomic disparities in smoking. Evidence on the equity impact of other interventions is inconclusive, with the exception of non-targeted smoking cessation programmes which have a negative equity impact due to higher quit rates among more advantaged smokers.

Conclusions Increased tobacco price via tax is the intervention with the greatest potential to reduce socioeconomic inequalities in smoking. Other measures studied appear unlikely to reduce inequalities in smoking without specific efforts to reach disadvantaged smokers. There is a need for more research evaluating the equity impact of tobacco control measures, and development of more effective approaches for reducing tobacco use in disadvantaged groups and communities.

\section{BACKGROUND}

While there is clear evidence for what works in reducing overall smoking levels, ${ }^{1}$ much less is known about the impact of tobacco control interventions on socioeconomic inequalities in smoking. ${ }^{2}$ In 2003, the World Bank described six cost-effective measures for reducing population tobacco use-namely, price increases, comprehensive bans on smoking in public and workplaces, bans on advertising and promotion of tobacco products, better consumer information (including mass media campaigns), warning labels on tobacco products, and help for smokers wanting to quit. ${ }^{1}$ These six approaches were incorporated in the
Framework Convention on Tobacco Control ${ }^{3}$ and now form the mainstay of global efforts to reduce tobacco-related harm. ${ }^{4}$

It is less clear how to reduce inequalities in smoking by socioeconomic status (SES). ${ }^{25}$ SES may be defined as a person's position in the social and economic structure of society, ${ }^{6}$ and is recognised as a key determinant of a person's 'life chances', including health. ${ }^{7}$ In most high-income countries, smoking prevalence has declined over the past 50 years with a particularly pronounced fall in higher socioeconomic groups; ${ }^{8} 9$ tobacco use remains stubbornly high in lower socioeconomic groups, ${ }^{10}{ }^{11}$ however, contributing to overall inequalities in health. ${ }^{12}$ There is now a wide body of research describing the uneven distribution of tobacco use by SES, ${ }^{5} 13$ but very little focusing on how to reduce these inequalities. ${ }^{14}$

Additionally, there is a lack of consensus over which policies to prioritise in tobacco control. ${ }^{15} 16$ Joossens and Raw developed a Tobacco Control Scale for evaluating tobacco control activities at a national level; this scale gives higher weights for price increases and smoke-free legislation and lower weights for warning labels and individual cessation support. ${ }^{17} 18$ The scale predicts national quit ratios (the proportion of ever-smokers who have quit smoking) $)^{19}$ and provides a useful indication of the relative importance attached to specific tobacco control interventions by a broad panel of experts (including researchers, policy-makers and civil society groups).

Two previous reviews have examined evidence on the impact of tobacco control measures by SES. ${ }^{20} 21$ Giskes et $a l^{20}$ undertook a literature review as part of their evaluation of the equity impact of tobacco control policies across six European countries. Based on 28 articles published between 1980 and 2004, the authors found limited evidence on the SES impact of specific tobacco control measures but hypothesised that price increases, smoking bans in workplaces, advertising bans and removing barriers to smoking cessation treatments all had the potential to reduce SES inequalities in smoking.

A more detailed systematic review was undertaken by the Centre for Reviews and Dissemination (CRD) at York University based on 84 studies published in academic and grey literature to January $2006^{21} 22$ and considering SES impact of tobacco control alongside other axes of equity (age, gender and race/ethnicity). The review considered 'population-level tobacco control interventions' 21 including price increases, workplace and school 
smoking bans, advertising bans and warning labels; cessation support and educational media campaigns were not considered. The authors found evidence of a pro-equity effect from tobacco price increases, but no evidence that other interventions were likely to reduce SES inequalities in smoking.

We aimed to review and synthesise existing evidence on the equity impact of tobacco control interventions by SES, building on the previous CRD review ${ }^{21}$ but expanding its focus to include educational media campaigns and smoking cessation services (ie, programmes offering formal assistance to smokers attempting to quit in the form of pharmacotherapy and/or behavioural or motivational support). Our review was conducted as part of a research project exploring tobacco control and smoking inequalities in England. ${ }^{23}$

\section{METHODS}

Our search strategy built on those used in two previous reviews $^{21} 2224$ which were modified to capture all six interventions described by the World Bank ${ }^{1}$ including price increases, smoke-free policies, advertising bans, educational media campaigns, warning labels and smoking cessation support, as well as community-based programmes combining two or more of the above (see online supplementary appendix for detailed search terms). Searches spanned January 2006 to September 2010 and covered 12 databases (BIOSIS; CINAHL Plus; Cochrane Library; DARE Database-including Health Technology Assessment Database and National Health Service (NHS) Economic Evaluation Database; EconLit; EMBASE; ISI Technology and Science Proceedings; Medline; PsycInfo; Science Citation Index; and the Social Science Citation Index). These were supplemented by hand-searching of four journals (Addiction; Nicotine and Tobacco Research; Social Science and Medicine; and Tobacco Control) from January 2009 to November 2010, including articles published online.

We included English language articles examining the impact of tobacco control interventions in adults (18 years and over) in countries at an advanced stage of the tobacco epidemic. ${ }^{8} 9$ Articles were excluded if they did not include data on SES impact (either the differential impact of tobacco control measures by SES or their impact in low-SES groups) or if the study population did not include adults. Reviews and primary research articles were included, although the latter were excluded if findings were already included via a review or more recent article. Where published reviews did not consider equity impact but included data from primary studies on SES impact, ${ }^{25} 26$ these primary studies were screened and articles meeting our inclusion criteria were included in this review. ${ }^{27-29}$ Besides publication in peer-reviewed journals no minimum criteria were set for study quality.

We identified 10345 articles, of which 4162 were duplicates and a further 91 not written in English (figure 1). One article could not be located, and a further 5336 were excluded on the basis of the title (ie, the title clearly indicated the article did not present results of original research or a systematic review featuring a tobacco control intervention directed at adults). Abstracts for the remaining 755 articles were evaluated against study criteria by two members of the study team; 380 were excluded based on abstracts and 286 were excluded following review of the full text. Of the remaining 89 articles, five primary studies were already included via systematic reviews: thus, a total of 84 articles (seven reviews and 77 research articles) were included in our review.

All articles were reviewed by two authors and details extracted using a standardised form. Standardised assessment of

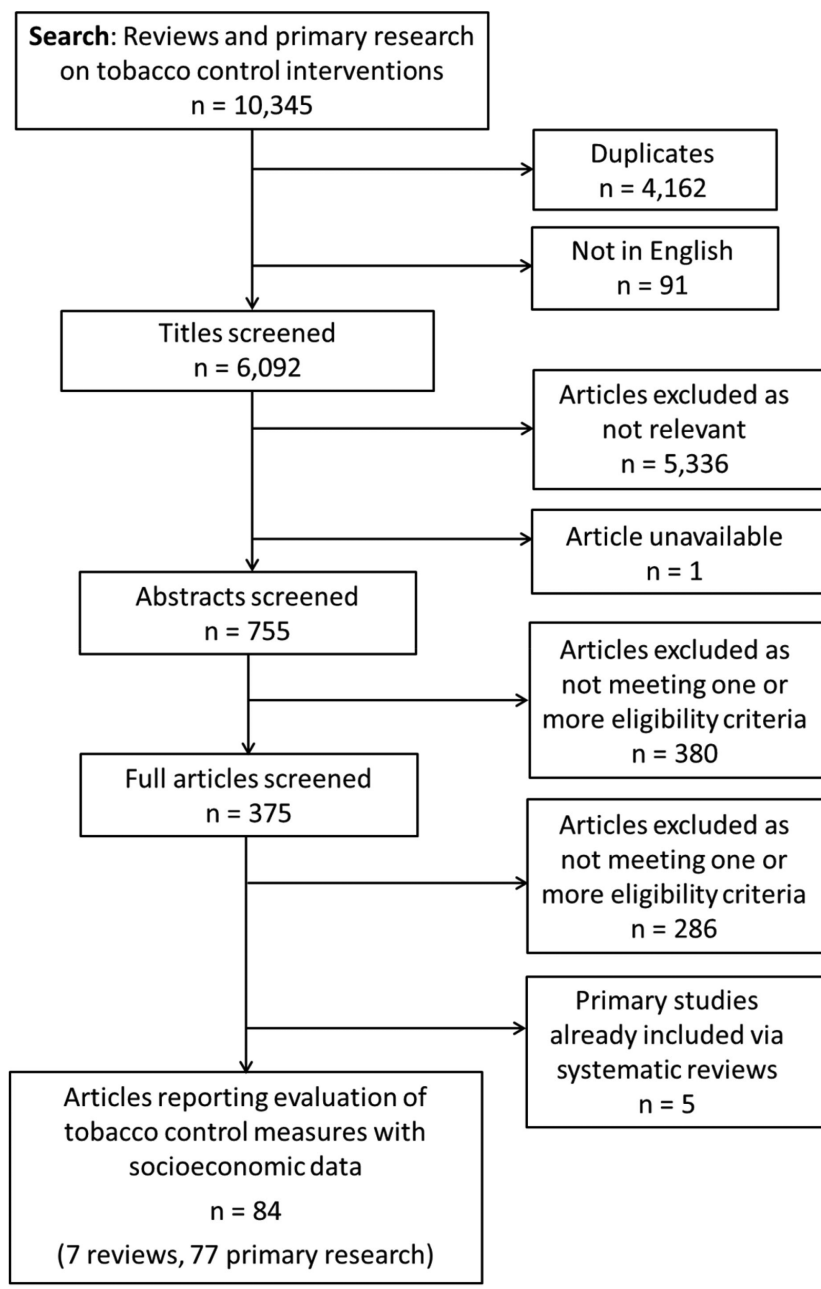

Figure 1 Study selection.

study quality was not attempted because of the diverse research methods employed; instead, individual studies were assessed in accordance with generic epidemiological principles relating to internal and external validity. ${ }^{30}$ Differences in assessment were resolved through discussion and consensus, involving all four authors where necessary.

Evidence was summarised via narrative synthesis. In synthesising data on the equity impact of specific interventions, evidence was judged to be stronger where the following criteria were met: (i) the internal and external validity of individual studies were considered to be high; (ii) the study design demonstrated a temporal relationship between the intervention and outcome under study; (iii) study outcomes included measures of actual smoking behaviour (rather than relying on intermediate measures such as awareness, programme participation or selfreported perceptions); and (iv) consistent results were obtained across several studies.

\section{RESULTS}

Over half the articles identified in this review examined the equity impact of smoking cessation support. In contrast, we found no published studies examining the impact of advertising bans or health warnings by SES. A modest number of studies examined equity impact of price increases, smoke-free environment policies and education campaigns, while only four focused on multi-faceted interventions delivered at the community level (see table 1). 
Table 1 Studies reviewed by intervention type

\begin{tabular}{lllc}
\hline Intervention & Reviews & $\begin{array}{l}\text { Primary } \\
\text { research }\end{array}$ & Total \\
\hline Price increases & $2^{*}$ & $7^{*}$ & $9^{*}$ \\
Smoke-free environments & $1^{*}$ & $12^{*}$ & $13^{*}$ \\
Educational media campaigns & 3 & $12^{*}$ & $15^{*}$ \\
Advertising bans & - & - & - \\
Health warnings & - & - & - \\
Smoking cessation support & 2 & $44^{*}$ & $46^{*}$ \\
Multifaceted approaches & - & 4 & 4 \\
(community-based programmes) & & & \\
All interventions & 7 & 77 & 84 \\
\hline
\end{tabular}

*The sum of study numbers listed in each column (Reviews, Primary research, Total) is greater than the total given in the final row (All interventions) because one review $^{20}$ and one primary study ${ }^{19}$ examined the impact of both price increases and smoke-free environments while another study examined the impact of both an educational media campaign and cessation support. ${ }^{31}$

Most articles reported quantitative results from observational or intervention studies of individual tobacco control interventions; very few used qualitative methods. ${ }^{32} 33$ Outcomes ranged from smoking prevalence and quit ratios to more intermediate measures such as awareness of health messages, contact with services, quit attempts and quit rates. Studies employed a wide variety of SES indicators including income, education, occupational class, health insurance status (in the USA) and area-level deprivation.

Since the majority of studies focused on the impact of single interventions, results are presented by intervention type with a final section describing multifaceted approaches (multiple tobacco control interventions delivered simultaneously at a community level). One review ${ }^{20}$ and one primary study ${ }^{19}$ examined the impact of several tobacco control measures by education; results from these are presented separately in the relevant sections. Schaap et al also sought to examine the collective impact of multiple national policies via the Tobacco Control Scale ${ }^{17}$ using cross-sectional data from 18 European countries. ${ }^{19}$ While higher educated smokers were more likely to have quit smoking in all 18 countries, the authors did not find conclusive evidence that this educational disparity was related to national tobacco control policies.

\section{PRICE INCREASES}

Based on seven primary studies, the CRD review identified tobacco price increases as the intervention with the greatest potential to reduce SES inequalities in adults. ${ }^{21}$ We identified a further two reviews ${ }^{20} 34$ and seven primary studies ${ }^{19} 33 \quad 35-39$ examining the impact of tobacco price increases by SES. The most recent of the two reviews ${ }^{34}$ supported the hypothesis that price increases have a greater impact on tobacco use in lowincome compared with high-income groups. ${ }^{40-42}$ An earlier review $^{20}$ reported greater price-responsiveness among manual compared with white-collar workers, ${ }^{43}$ but also noted evidence that smokers in low-SES groups may substitute lower cost or roll-your-own cigarettes when the price of manufactured cigarettes increases. ${ }^{44}$

Three primary studies evaluated the impact of tobacco price increases by income and found evidence of greater price-responsiveness in low-income smokers. ${ }^{35-37}$ Franks et al ${ }^{37}$ reported a decline in price-sensitivity in all income groups over time, and suggest that the effectiveness of price increases may diminish with increasing baseline tobacco price. One study reported that low-income smokers were less responsive to increases in cigarette price, but the validity of this finding is limited by small sample size and likely response bias. ${ }^{33}$ Evidence on impact by education was more mixed, with two studies reporting greater price responsiveness in low-education smokers $^{36} 38$ and two finding either no difference or slightly greater price-responsiveness in middle- and high-education groups. 1939

\section{SMOKE-FREE ENVIRONMENTS}

The CRD review identified 14 studies evaluating smoking bans in public or workplaces. ${ }^{21}$ The authors found no evidence of a differential effect by education or income, but weak evidence that workplace smoking restrictions may be more effective for higher occupational groups. We identified one further review ${ }^{20}$ and a further 12 primary studies evaluating the impact of smoking restrictions by SES. ${ }^{19}$ 45-55

Giskes et $a l^{20}$ found several studies supporting the contention that workplace smoking restrictions reduce workers' tobacco exposures, but only one that considered their impact by SES. This study (not included in the CRD review) found that smoking restrictions were more likely to be implemented in professional than in manual workplaces. ${ }^{56}$ Further evidence of uneven implementation comes from five studies examining workplace smoking restrictions in the presence of national or state level legislation. ${ }^{45-49}$ Higher educated workers in California and the Netherlands were more likely to benefit from the introduction of smoke-free workplace legislation in terms of reduced exposure to secondhand smoke (SHS) ${ }^{45-47}$ and increased smoking cessation. ${ }^{46} 47$ There is weak evidence that legislation banning smoking in pubs and restaurants is less likely to be enforced in disadvantaged areas ${ }^{48}$ and more likely to benefit higher-income staff. ${ }^{49}$

A few studies demonstrated benefits in overall tobacco exposure following introduction of smoke-free legislation. None of these demonstrated differential impact by SES, although they may have been underpowered to do so. Evaluation of comprehensive smoke-free legislation in Scotland and England showed increased cessation ${ }^{50}$ and decreased SHS exposure ${ }^{52}$ in public and workplaces following implementation, but no evidence of differential impact by SES-possibly reflecting limited study power at a subpopulation level. Similarly, Schaap et $a l^{19}$ found higher quit ratios in those European countries with workplace/ public smoking bans, but no evidence of a differential effect by education.

A lack of legislation is associated with more pronounced SES gradients in 'voluntary' (non-legislated) workplace smoking restrictions. ${ }^{53}$ This might be interpreted as indirect evidence that comprehensive smoke-free legislation has the potential to reduce SES gradients in workplace SHS exposure (ie, a pro-equity effect) - a possibility consistent with qualitative evaluation of smoke-free legislation in Scotland, which found the most marked changes occurred among smokers living in disadvantaged areas. ${ }^{32}$ Adverse effects of legislation may also be more pronounced in disadvantaged smokers, however, as suggested by evidence that smoke-free legislation in England encouraged smokers to quit but may have increased social isolation among older smokers. ${ }^{55}$

Overall, there is mixed evidence on the impact of smoke-free legislation on socioeconomic inequalities in tobacco exposure in public or workplaces. Several cross-sectional studies demonstrate higher workplace exposure to tobacco smoke among less advantaged social groups, ${ }^{45-4756}$ but the effect of smoke-free legislation on this gradient is unclear since evaluations assessing 
exposure before and after legislation have failed to demonstrate a differential impact. ${ }^{50-52}$

\section{EDUCATIONAL AND MEDIA CAMPAIGNS}

Three reviews ${ }^{57-59}$ and 12 primary studies ${ }^{28} \quad 31 \quad 60-69$ (not included in the CRD review ${ }^{21}$ ) examined the impact of mass media health education and smoking cessation campaigns. Overall, evidence for a differential impact by SES was inconclusive.

The most relevant of the three reviews focused on the effectiveness of mass media campaigns for low-SES groups, based on 50 predominantly US studies. ${ }^{57}$ Population-based media campaigns were generally found to have lower impact among low-SES smokers, while campaigns targeting low-SES smokers showed no clear impact on smoking behaviour. The authors concluded that media campaigns were 'often less effective, sometimes equally effective, but rarely more effective' in promoting cessation among disadvantaged populations, and may therefore inadvertently contribute to inequalities in smoking. ${ }^{57}$

Two Cochrane reviews evaluated the overall effectiveness of mass media smoking cessation campaigns-both with ${ }^{59}$ and without $^{58}$ incentives-although neither included an explicit focus on impact by SES. Both reviews included studies examining SES indicators as predictors of smokers' responsiveness, but findings were inconclusive-possibly reflecting limitations in the study design and explanatory power. ${ }^{58} 59$

\section{Multiple media}

We found seven studies examining the equity impact of smoking cessation campaigns conducted through multiple media, 31 64-69 none of which produced conclusive findings-in part because of mixed results, but also because of weak study design. Four US studies evaluated campaigns promoting local quit lines; ${ }^{64-67}$ while three reported greater quitline awareness among less educated smokers, ${ }^{65-67}$ only one examined smoking outcomesand found higher quit rates among high-income smokers. ${ }^{64} \mathrm{~A}$ Dutch study found greater campaign responsiveness among more educated smokers, ${ }^{31}$ while an evaluation of the UK's 'No Smoking Day' campaign reported similar responses by SES. ${ }^{68}$ Evaluation of a targeted campaign in Canada was inconclusive. $^{69}$

\section{Television}

Three US studies examined the impact of antismoking television campaigns by SES. ${ }^{60-62}$ These provide weak evidence that advertisements using personal testimony are more likely to have neutral equity impact compared with traditional informationbased advertisements, which tend to have greater impact among high-SES smokers.

\section{Internet}

Two US studies examined smoking cessation campaigns delivered via internet advertisements, but found little evidence of effectiveness among low-SES smokers. ${ }^{28} 63$

\section{HEALTH WARNINGS AND ADVERTISING BANS}

The CRD review found no consistent evidence that health warnings on tobacco products have an equity impact, ${ }^{21}$ although only two studies examined this in adults. ${ }^{70} 71$ We found no further studies examining the equity impact of health warnings, and (consistent with the CRD review) none examining advertising bans.

\section{SMOKING CESSATION SUPPORT}

We identified two reviews ${ }^{72} 73$ and 44 primary studies ${ }^{28} \quad 2931$ 74-114 that attempted to evaluate the SES impact of smoking cessation services.

\section{Behavioural and pharmacotherapy}

Two reviews ${ }^{72} 7^{73}$ and 20 primary studies ${ }^{74-93}$ examined the equity impact of smoking cessation services combining pharmacotherapy with behavioural support (either group based or one-to-one). Nine primary studies examined the differential impact of cessation services by SES, while 11 focused on interventions targeting low-SES populations.

Based on 20 studies of cessation support delivered through the UK NHS, Bauld et $a l^{72}$ reported consistently lower quit rates among smokers from deprived areas. Several services sought to address this inequity by concentrating cessation programmes in more deprived areas; while service uptake increased in targeted communities, actual quit rates remained lower than in more advantaged areas.

A second review focused on cessation services targeting disadvantaged groups. ${ }^{73}$ Access to services among low-SES smokers was shown to improve when these were targeted at disadvantaged areas, although the authors found limited evidence for increases in actual quitting.

A further nine primary studies examined the impact of combined pharmaco-behavioural therapy by SES, ${ }^{74-82}$ with most showing lower quit rates among low-SES smokers cessation programmes delivered through national health systems had consistently lower success among deprived smokers both in the $\mathrm{UK}^{74} 75$ and New Zealand ${ }^{77}$-although the New Zealand study showed targeting of deprived areas resulted in higher service uptake, which compensated for lower quit rates. Pharmaco-behavioural cessation programmes in the USA and Canada also reported lower quit rates among smokers from low-SES groups (measured by education, $^{78}$ self-rated social status ${ }^{79}$ and insurance status ${ }^{80}$ ). Evaluation of two inpatient smoking cessation interventions in the USA and Sweden found no conclusive differences by SES. ${ }^{81} 82$

A further 11 primary studies examined cessation programmes targeting low-SES populations, including three from the UK, ${ }^{83-85}$ seven from the USA ${ }^{86-92}$ and one from Australia. ${ }^{93}$ UK research showed very low quit rates among low-SES smokers despite high levels of interest, ${ }^{83} 85$ although one Scottish programme reported quite high quit rates cessation among young pregnant women from deprived communities. ${ }^{84}$ US-based research largely comprised small studies recruiting smokers from low-income neighbourhoods or health services aimed at low-income groups, often including a high proportion of ethnic minorities. Several targeted cessation trials in the USA ${ }^{86} 888992$ and one in Australia ${ }^{93}$ reported relatively high quit rates, although these studies were generally small (100 participants or fewer). Two larger studies ${ }^{87}$ 91 targeted 'disadvantaged' communities but attracted smokers with a range of SES; both reported greater success among high-SES individuals. ${ }^{91} 87$

\section{Behavioural therapy}

Six primary studies evaluated behavioural support without pharmacotherapy, including three evaluating equity impact in broad population groups ${ }^{94-96}$ and three targeting low-SES groups. ${ }^{97-99}$

Successful quitting was associated with higher education in two North American studies evaluating behavioural support among healthcare users, including pregnant smokers in New York $^{94}$ and patients admitted to a coronary care unit in 
Canada. ${ }^{95}$ Similarly, a study focusing on rural smokers in Kansas found higher levels of engagement among participants with higher education and income levels. ${ }^{96}$

Three studies targeting low-SES groups (including pregnant women in the USA, ${ }^{97}$ low-income women in Canada, ${ }^{99}$ and blue-collar workers in the USA and Canada ${ }^{98}$ ) provide weak evidence that behavioural therapies promote smoking cessation in these groups-although since two of the three studies did not provide data on the SES profile of programme participants, it is unclear to what extent these programmes actually reached their target populations. ${ }^{97} 98$

\section{Pharmacotherapy}

Two primary studies explored the equity impact of pharmacotherapy as a stand-alone intervention. ${ }^{100} 101$ One reported greater relapse among smokers with lower occupational class and education, ${ }^{101}$ while results from the other are difficult to interpret in relation to SES since participants had a mixed profile (including low income and employment but high education). ${ }^{100}$

\section{Telephone-based support}

Five studies examined SES impact of telephone-based cessation support (quitlines), including three from the USA ${ }^{102} 103105$ and two from Australia. ${ }^{104} 106$ Three of these studies aimed to evaluate the impact of quitline support by SES, ${ }^{102}{ }^{103}$ while two assessed the effectiveness of quitlines for low-income smokers. ${ }^{105} 106$

Studies evaluating the effectiveness of quitline services by SES suggest that smokers with higher education are more likely to quit using these services, although evidence is sparse and findings are mixed. An evaluation of quitline recruitment in Australia found those agreeing to use the quitline were more likely to have university-level qualifications compared with the general profile of smokers in the region, ${ }^{104}$ while evaluation of a quitline in Minnesota found smokers with university-level qualifications were more likely to succeed in quitting. ${ }^{102}$ In contrast, evaluation of a Washington state quitline found no difference in self-reported quitting by education. ${ }^{103}$

Two studies provide weak evidence of the effectiveness of quitlines in low-SES smokers. ${ }^{105} 106$ An Australian study found very low recruitment among smokers from less advantaged neighbourhoods, but quit rates among participants were 'comparable to other studies of 'mainstream' smokers'. ${ }^{106}$ A New York study examined the impact of a state quitline (and smoke-free legislation) in a cohort of low-income smokers, but very low follow-up (less than 40\%) made results difficult to interpret. ${ }^{105}$

\section{Internet-based support}

Emerging evidence suggests internet-based support may assist smokers' attempts to quit. ${ }^{25}$ Findings from five primary studies suggest such support is likely to have a negative equity impact, ${ }^{28} 29$ 107-109 since smokers with higher educational attainment are more likely to engage with ${ }^{2829} 107$ and successfully quit ${ }^{109}$ through webbased programmes.

\section{Brief interventions}

Brief interventions refer to health professionals' 'opportunistic advice, discussion, negotiation or engagement ${ }^{115}$ with smokers to encourage cessation. Giskes et $a l^{20}$ noted that brief interventions are less likely to reduce smoking in low-SES groups since these individuals are less likely to visit their family practitioner for preventive-health reasons. We identified a further three primary studies ${ }^{110-112}$ which indicate that brief interventions have limited effectiveness in low-SES smokers.

Based on national survey data, researchers in the USA reported a positive association between brief cessation advice and quitting; however, quitting was less likely among loweducation smokers. ${ }^{110}$ Two cohort-based evaluations showed limited or no impact from brief interventions in low-SES women: one found women smokers attending public health clinics were more motivated to quit but no more likely to be abstinent following a brief intervention, ${ }^{111}$ while the other found no effect from brief cessation interventions among loweducation women. ${ }^{112}$

\section{Other support}

Three primary studies examined unusual forms of cessation intervention that did not fit any of the above categories. ${ }^{31} 113114$ Successful quitting was associated with higher education in studies of incentivised ${ }^{31}$ and psychologically-tailored cessation support; ${ }^{113}$ a very small trial of automated telephone follow-up found no evidence of any equity impact. ${ }^{114}$

\section{MULTI-FACETED APPROACHES (COMMUNITY-BASED PROGRAMMES)}

Very few studies have examined interventions using a combination of approaches to reduce adult smoking. We identified four primary evaluations of multi-faceted approaches, ${ }^{27}$ 116-118 with limited evidence of any effect.

The most promising of these studies was an ecological evaluation of New York City's comprehensive tobacco control programme (including taxation, smoke-free legislation, education and promotion of cessation services), focusing on smoking in young adults. ${ }^{18-24} 118$ Young adult smoking declined in the 3 years following the programme, with greater reductions in low-income neighbourhoods. While these results are encouraging, their validity is somewhat limited by the evaluation's reliance on repeat cross-sectional data which does not account for population mobility (likely to be particularly high in this group).

A 2008 Cochrane review found limited evidence that community interventions reduce smoking prevalence in adults. ${ }^{26}$ The review did not explicitly examine the SES impact of such interventions, although one primary study (focused on women in New England) reported high quitting among low-income smokers in response to a targeted intervention. ${ }^{27}$

Two studies from the Netherlands evaluated community interventions targeting several health behaviours (including smoking) in deprived areas. ${ }^{116} 117$ Neither found evidence of reduced smoking prevalence in these communities.

\section{DISCUSSION}

We identified 84 articles (including 77 primary studies and seven reviews) that included some assessment of the impact of tobacco control measures by SES and that were not included in a previously published review. ${ }^{21} 22$ Over half ${ }^{46}$ of these articles focused on cessation support, with far fewer examining equity impact of price increases, ${ }^{9}$ smoke-free environments, ${ }^{13}$ media campaigns ${ }^{15}$ or community-based approaches. ${ }^{4}$ No new studies assessed the SES impact of advertising bans or health warnings.

As with the previous CRD review, ${ }^{21}$ our review provided strong evidence that increases in tobacco price have a pro-equity effect on the SES gradient in smoking (table 2). Increased tobacco price (via tax) is the only one of six tobacco control interventions described by the World Bank ${ }^{1}$ to have a clear pro-equity effect. Evidence on the impact of two other interventions is somewhat mixed. Workplace exposure to tobacco smoke is 
Table 2 Summary of evidence for equity impact of tobacco control interventions

\begin{tabular}{|c|c|c|c|}
\hline Intervention & $\begin{array}{l}\text { TCS } \\
\text { weighting* }\end{array}$ & $\begin{array}{l}\text { Likely equity } \\
\text { impact } t\end{array}$ & Strength of evidence \\
\hline Price increases & 30 & Positive & $\begin{array}{l}\text { Strong evidence of greater price-responsiveness in low-income groups. }{ }^{20} 34-37 \text { Mixed evidence in relation } \\
\text { to impact by education }{ }^{19} 363839\end{array}$ \\
\hline Smoke-free environments & 22 & Mixed & $\begin{array}{l}\text { Consistent evidence that workplace exposure to tobacco smoke is higher among less advantaged social } \\
\text { groups, }{ }^{45-4756} \text { but no clear evidence on how the introduction of smoke-free legislation may affect this } \\
\text { gradient (since evaluative studies have not demonstrated a differential impact by SES }{ }^{50-52} \text { ) }\end{array}$ \\
\hline $\begin{array}{l}\text { Educational media } \\
\text { campaigns }\end{array}$ & 15 & Mixed & $\begin{array}{l}\text { Mixed evidence base. Several studies suggest media campaigns are less effective among low-SES groups. }{ }^{57} \\
\text { Some evidence that advertisements using personal testimony may do better in reaching low-SES smokers; } \\
\text { of more traditional advertisments }{ }^{60} 61\end{array}$ \\
\hline Advertising bans & 13 & - & No evidence \\
\hline Health warnings & 10 & - & No evidence \\
\hline $\begin{array}{l}\text { Smoking cessation } \\
\text { support }\end{array}$ & 10 & Negative & $\begin{array}{l}\text { Consistent evidence of lower quit rates in low-SES smokers using cessation services. }{ }^{24} 72747578-8094- \\
96101109 \text { Negative equity impact may be attenuated by concentrating services in more deprived areas }\end{array}$ \\
\hline $\begin{array}{l}\text { Multi-faceted } \\
\text { (community-based) }\end{array}$ & NA & No clear effect & Very limited evidence \\
\hline
\end{tabular}

known to be higher among less advantaged social groups, ${ }^{45-47} 56$ but there is no clear evidence on the equity impact of introducing comprehensive smoke-free legislation. ${ }^{50-52}$ Evidence on the SES impact of media campaigns is scarce; a majority of studies suggest that such campaigns are less effective among low-SES groups, ${ }^{57}$ although some studies suggest campaigns including personal testimony may be more effective in reaching low-SES smokers. ${ }^{60} 61$

There is consistent evidence that mainstream smoking cessation services produce higher quit rates among high-SES smokers, ${ }^{24} 72$ 74 75 78-80 94-96 101109 and are therefore unlikely to reduce inequalities in smoking. A small number of studies have demonstrated that cessation services can achieve greater effectiveness in low-SES smokers by concentrating support in less advantaged communities, and that, where such targeting occurs, increased recruitment among low-SES smokers can compensate for lower quit rates. ${ }^{72} 76$ In disadvantaged communities, high levels of interest did not always translate into successful quitting. ${ }^{83} 85$ While some small studies report more positive results, ${ }^{86} 88-90$ we agree with previous reviewers ${ }^{14}$ that studies examining cessation services in disadvantaged groups are often limited by weak design. Targeted cessation services may have a role to play in reducing smoking inequalities, but more work needs to be done in developing support programmes tailored to low-SES smokers.

An important outcome of this review is confirmation of the limited evidence base examining the impact of tobacco control measures by SES. ${ }^{2} 1421$ Much of the evidence reviewed came from studies where an intervention's equity impact was not the primary evaluative aim: since most studies are neither designed nor adequately powered to address this, negative findings are difficult to interpret. ${ }^{50-52}$ A second, and equally important, limitation is the scarcity of research examining tobacco control interventions other than cessation support. This is particularly regrettable given price increases and smoke-free environments legislation are thought to be the most effective tobacco control interventions at a population level, while cessation support is of more modest significance. ${ }^{17} 18$ Third, a majority of studies sought to evaluate the impact of a single intervention, whereas tobacco control is typically multi-faceted with several interventions developing in parallel in a particular jurisdiction. This makes it difficult (and perhaps unrealistic) to distinguish between the effects of different components in a tobacco control programme; yet, we found only four studies that attempted to evaluate the SES impact of multi-faceted population-level approaches, ${ }^{27}$ 116-118 while a previous review found none. ${ }^{21}$

These limitations reflect broader challenges in developing an effective evidence base for tackling health inequalities. ${ }^{119}$ Health researchers are often drawn to study designs featuring experimental interventions and individual health behaviours (the classical randomised control trial) since these are easier to undertake and analyse, and are often regarded as more 'robust' in generating evidence of causality. ${ }^{120}{ }^{121}$ Population-level interventions-including legislation, media campaigns and multifaceted programmes - are more difficult to evaluate since they are almost never randomly assigned, their implementation depends on local context and their impact (both planned and unplanned) are typically diffuse. ${ }^{122}$ Yet, these upstream interventions offer the most promise for reducing inequalities in health (including tobacco use), ${ }^{123}$ meaning policy-makers require the kinds of 'messy' evidence produced by observational and ecological studies. We need greater investment in these kinds of research (particularly studies following communities over a period of time) and a broader understanding of the kinds of evidence that can inform policy development in tobacco control. $^{124}$

By limiting our review to English language literature and studies of adults, we may have excluded some relevant evidence. Evaluation of the 2006 Scottish smoke-free legislation found a positive equity impact on SHS exposure among primary school children, ${ }^{125}$ an encouraging result that may have implications for low-SES adults. The previous CRD review included studies focused on children and young people but found no evidence on differential effects by parental income, occupation or educational level. ${ }^{21}$ Given the importance of smoking uptake in driving overall prevalence, there is clearly a need for more research on the SES impact of tobacco control measures in children and young people.

\section{CONCLUSIONS}

There is strong evidence that increases in tobacco price have a pro-equity effect on smoking behaviour. Other tobacco control measures are unlikely to help reduce inequalities in smoking without specific efforts to make these more accessible and 
effective for disadvantaged smokers. There is a need for more research evaluating the equity impact of population-level tobacco control measures, particularly multi-faceted approaches and those targeting less advantaged communities.

\section{What is already known on this subject}

- While overall smoking prevalence has fallen in most high-income countries, there are substantial inequalities in tobacco use by socioeconomic status (SES).

- There is a lack of clear evidence regarding the impact of tobacco control interventions on SES inequalities in tobacco use.

\section{What this paper adds}

- Increased tobacco price is the only tobacco control intervention shown to have a clear pro-equity impact on smoking.

- Mainstream non-targeted smoking cessation programmes appear to have a negative equity impact on socioeconomic status (SES) inequalities in smoking due to their greater effectiveness among high-SES smokers.

- More research is needed to identify interventions and strategies with the potential to reduce SES inequalities in tobacco use.

Acknowledgements The authors would like to thank Rosemary Hiscock and Linda Bauld for giving access to their unpublished review of socioeconomic status and smoking cessation interventions; the Centre for Reviews and Dissemination (CRD) at York University for sharing the search strategy used in their review; and Heide Weishaar for assistance in reviewing abstracts.

Contributors AA, SP and SH developed the initial strategy for the review; $D C$ undertook the literature search with support from AA, SP and SH; DC, SH, AA and SP reviewed individual articles; SH wrote the first draft of this paper; $A A, S P$ and DC contributed to the writing of the manuscript and agree with its results and conclusions.

Funding This review is based on work undertaken as part of a project exploring tobacco control and smoking inequalities in England undertaken by the UK Public Health Research Consortium and funded by the UK Department of Health Policy Research Programme.

Competing interests None.

Provenance and peer review Not commissioned; externally peer reviewed.

\section{REFERENCES}

1 World Bank. Tobacco control at a glance. Washington, DC: World Bank, 2003.

2 Main C, Thomas S, Ogilvie D, et al. Population tobacco control interventions and their effects of social inequalities in smoking: placing an equity lens on existing systematic reviews. BMC Public Health 2008;1:178.

3 WHO. WHO framework convention on tobacco control. Geneva: WHO, 2003.

4 WHO. Guidelines for the implementation of Article 5.3 of the WHO Framework Convention on Tobacco Control. Geneva: WHO, 2008.

5 Hiscock R, Bauld L, Amos A, et al. Smoking and socioeconomic status in England: the rise of the never smoker and the disadvantaged smoker. J Public Health 2012;34:390-6.

6 Bartley M. Health inequality: an introduction to theories, concepts and methods. Cambridge: Polity Press, 2004.

7 Lynch JW, Kaplan G. Socioeconomic position. In: Berkman L, Kawachi I. eds. Social epidemiology. New York: Oxford University Press, 2000:13-35.
8 Lopez A, Collishaw N, Piha T. A descriptive model of the cigarette epidemic in developed countries. Tob Control 1994;3:242-7.

9 Thun M, Peto R, Boreham J, et al. Stages of the cigarette epidemic on entering its second century. Tob Control 2012;21:96-101.

10 Giskes K, Kunst A, Benach J, et al. Trends in smoking behaviour between 1985 and 2000 in nine European countries by education. J Epidemiol Community Health 2005;59:395-401.

11 Mackenbach J, Stirbu I, Roskam A, et al. Socioeconomic inequalities in health in 22 European countries. N Engl J Med 2008;358:2468-81.

12 Marmot M. Smoking and inequalities. Lancet 2006;368:341-2.

13 Jarvis M, Wardle J. Social patterning of individual health behaviours: the case of cigarette smoking. In: Marmot M, Wilkinson R, eds. Social Determinants of Health 2nd edn. Oxford: Oxford University Press, 2003:225-37.

14 Bryant J, Bonevski B, Paul C. A systematic review and meta-anaysis of the effectiveness of behavioural smoking cessation interventions in selected disadvantaged groups. Addiction 2011;106:1568-85.

15 WHO. Global progress report on implementation of the WHO framework convention on tobacco control. Geneva: WHO Framework Convention on Tobacco Control Secretariat, 2010.

16 Warner K. Disparities in smoking are complicated and consequential. What to do about them? Am J Health Promot 2011;25(5S):S5-7.

17 Joossens L, Raw M. The Tobacco Control Scale: a new scale to measure country activity. Tob Control 2006:15:247-53.

18 Joossens L, Raw M. The Tobacco Control Scale 2010 in Europe. Brussels: Association of European Cancer Leagues, 2011.

19 Schaap M, Kunst A, Leinsalu $M$, et al. Effect of nationwide tobacco control policies on smoking cessation in high and low educated groups in 18 European countries. Tob Control 2008; 17:248-55.

20 Giskes K, Kunst A, Ariza C, et al. Applying an equity lens to tobacco-control policies and their uptake in six western-European countries. J Public Health Policy 2007;28:261-80.

21 Thomas S, Fayter D, Misso K, et al. Population tobacco control interventions and their effects on social inequalities in smoking: systematic review. Tob Control 2008; 17:230-7.

22 Fayter D, Main C, Misso K, et al. Population tobacco control interventions and their effects on social inequalities in smoking. York: Centre for Reviews and Dissemination, University of York, 2008.

23 Amos A, Bauld L, Hill S, et al. Tobacco control, inequalities in health and action at the local level in England. London: Public Health Research Consortium, 2011.

24 Hiscock R, Bauld L. Socioeconomic status and smoking cessation interventions [unpublished report]. Bath: University of Bath, 2009.

25 Civljak M, Sheikh A, Stead L, et al. Internet-based interventions for smoking cessation. Cochrane Database Syst Rev 2010;(9):CD007078.

26 Secker-Walker R, Gnich W, Platt S, et al. Community interventions for reducing smoking among adults. Cochrane Database Syst Rev 2008:5:CD001745.

27 Secker-Walker R, Flynn B, Solomon L, et al. Helping women quit smoking: results of a community intervention program. Am J Public Health 2000;90:940-6.

28 McKay H, Danaher B, Seeley J, et al. Comparing two web-based smoking cessation programs: randomized controlled trial. J Med Internet Res 2008;10:e40.

29 McClure J, Greene S, Wiese C, et al. Interest in an online smoking cessation program and effective recruitment strategies: results from Project Quit. J Med Internet Res 2006;8:e14.

30 Rothman KJ, Greenland S. Modern epidemiology. 2nd edn. Philadelphia: Lippincott-Raven Publishers, 1998.

31 van Osch L, Lechner L, Reubsaet $A$, et al. Optimizing the efficacy of smoking cessation contests: an exploration of determinants of successful quitting. Health Educ Res 2009;24:54-63.

32 Ritchie D, Amos A, Martin C. Public places after smoke-free-a qualitative exploration of the changes in smoking behaviour. Health Place 2010;16:461-9.

33 Peretti-Watel P, Constance J. "It's all we got left". Why poor smokers are less sensitive to cigarette price increases. Int J Environ Res Public Health 2009;6:608-21.

34 Chaloupka F, Straif K, Leon M. Effectiveness of tax and price policies in tobacco control. Tob Control 2011;20:235-8.

35 Colman G, Remler D. Vertical equity consequences of very high cigarette tax increases: if the poor are the ones smoking, how could cigarette tax increases be progressive? J Policy Anal Manag 2008;27:376-400.

36 DeCicca P, McLeod L. Cigarette taxes and older adult smoking: evidence from recent large tax increases. J Health Econ 2008;27:918-29.

37 Franks P, Jerant A, Leigh J, et al. Cigarette prices, smoking, and the poor: implications of recent trends. Am J Public Health 2007;97:1873-7.

38 Levy D, Mumford E, Compton C. Tobacco control policies and smoking in a population of low education women, 1992-2002. J Epidemiol Community Health 2006:60(suppl 2):ii20-6.

39 Madden D. Tobacco taxes and starting and quitting smoking: does the effect differ by education? Appl Econ 2007;39:613-27.

40 Siahpush M, Wakefield M, Spittal M, et al. Taxation reduces social disparities in adult smoking prevalence. Am J Prev Med 2009;36:285-91. 
41 Farrelly MC, Bray JW, Pechacek T. Responses by adults to increases in cigarette prices by sociodemographic characteristics. South Econ J 2001;68:156-65.

42 Townsend J, Roderick P, Cooper J. Cigarette smoking by socioeconomic group, sex, and age: effects of price, income, and health publicity. BMJ 1994;309: 923-7.

43 Townsend J. Price and consumption of tobacco. Br Med Bull 1996;52:132-42.

44 Mindell J, Whynes D. Cigarette consumption in the Netherlands 1970-1995. Does tax policy encourage the use of hand-rolling tobacco? Eur J Public Health 2000;10:214-19.

45 Tong $\mathrm{E}$, Tang $\mathrm{H}$, Tsoh J, et al. Smoke-free policies among Asian-American women: comparisons by education status. Am J Prev Med 2009;37(2S):S144-50.

46 Verdonk-Kleinjan W, Knibbe R, Tan F, et al. Does the workplace-smoking ban eliminate differences in risk for environmental tobacco smoke exposure at work? Health Policy 2009;92:197-202.

47 Nagelhout $G$, Willemsen $M$, de Vries $H$. The population impact of smoke-free workplace and hospitality industry legislation on smoking behaviour. Findings from a national population survey. Addiction 2011;106:816-23.

48 Moore R, Annechino R, Lee J. Unintended consequences of smoke-free bar policies for low-SES women in three California counties. Am J Prev Med 2009;37(S Suppl):S138-43.

49 Braverman M, Aaro L, Hetland J. Changes in smoking among restaurant and bar employees following Norway's comprehensive smoking ban. Health Promot Int 2008;23:5-15.

50 Fowkes $F$, Stewart M, Fowkes $F$, et al. Scottish smoke-free legislation and trends in smoking cessation. Addiction 2008:103:1888-95.

51 Hackshaw L, McEwen A, West R, et al. Quit attempts in response to smoke-free legislation in England. Tob Control 2010;19:160-4.

52 Hyland A, Hassan L, Higbee $C$, et al. The impact of smokefree legislation in Scotland: results from the Scottish ITC Scotland/UK longitudinal surveys. Eur $J$ Public Health 2009;19:198-205.

53 Shavers V, Fagan P, Alexander L, et al. Workplace and home smoking restrictions and racial/ethnic variation in the prevalence and intensity of current cigarette smoking among women by poverty status, TUS-CPS 1998-1999 and 2001-2002. J Epidemiol Community Health 2006:60:34-43.

54 Friedrich V, Bruegger A, Bauer G. Worksite tobacco prevention in the Canton of Zurich: stages of change, predictors, and outcomes. Int J Public Health 2009;54:427-38.

55 Lock K, Adams E, Pilkington P, et al. Evaluating social and behavioural impacts of English smoke-free legislation in different ethnic and age groups: implications for reducing smoking-related health inequalities. Tob Control 2010;19: 391-7.

56 Brenner H, Born J, Novak P, et al. Smoking behaviour and attitude toward smoking regulations and passive smoking in the workplace: a study among 974 employees in the German metal industry. Prev Med 1997;26:138-43.

57 Niederdeppe J, Kuang $X$, Crock B, et al. Media campaigns to promote smoking cessation among socioeconomically disadvantaged populations: what do we know what do we need to learn, and what should we do now? Soc Sci Med 2008;67:1343-55.

58 Bala M, Strzeszynski L, Cahill K. Mass media interventions for smoking cessation in adults. Cochrane Database Syst Rev 2008;1:CD004704.

59 Cahill K, Perera R. Quit and Win contests for smoking cessation. Cochrane Database Syst Rev 2008:(4):CD004986.

60 Niederdeppe J, Fiore M, Baker T, et al. Smoking-cessation media campaigns and their effectiveness among socioeconomically advantaged and disadvantaged populations. Am J Public Health 2008;98:916-24.

61 Durkin S, Biener L, Wakefield M. Effects of different types of antismoking ads on reducing disparities in smoking cessation among socioeconomic subgroups. Am J Public Health 2009:99:2217-23.

62 Davis K, Nonnemaker J, Farrelly M, et al. Exploring differences in smokers' perceptions of the effectiveness of cessation media messages. Tob Control 2011;20:26-33.

63 Graham A, Milner P, Saul J, et al. Online advertising as a public health and recruitment tool: comparison of different media campaigns to increase demand for smoking cessation interventions. J Med Internet Res 2008;10:e50.

64 Maher J, Rohde K, Pizacani B, et al. Does free nicotine replacement therapy for young adults prompt them to call a quitline? Tob Control 2007;16:357-8.

65 Cummins S, Hebert K, Anderson C, et al. Reaching young adult smokers through quitlines. Am J Public Health 2007;97:1402-5.

66 Czarnecki K, Vichinsky L, Ellis J, et al. Media campaign effectiveness in promoting a smoking-cessation program. Am J Prev Med 2010;3(Suppl):S333-342.

67 Burns E, Levinson A. Reaching Spanish-speaking smokers: state-level evidence of untapped potential for QuitLine utilization. Am J Public Health 2010;100(S1): s165-70.

68 Owen L, Youdan B. 22 years on: the impact and relevance of the UK No Smoking Day. Tob Control 2006;15:19-25.

69 Gagne L. The 2005 British Columbia smoking cessation mass media campaign and short-term changes in smoking. J Public Health Manag and Pract 2007:13:296-306
70 Borland R, Hill D. Initial impact of the new Australian tobacco health warnings on knowledge and beliefs. Tob Control 1997;6:317-25.

71 Willemsen $\mathrm{M}$. The new EU cigarette health warnings benefit smokers who want to quit the habit: results from the Dutch Continuous Survey of Smoking Habits. Eur J Public Health 2005;15:389-92.

72 Bauld L, Bell K, McCullough L, et al. The effectiveness of NHS smoking cessation services: a systematic review. J Public Health 2010;32:71-82.

73 Murray R, Bauld L, Hackshaw L, et al. Improving access to smoking cessation services for disadvantaged groups: a systematic review. J Public Health 2009:31:258-77.

74 Bauld L, Chesterman J, Ferguson J, et al. A comparison of the effectiveness of group-based and pharmacy-led smoking cessation treatment in Glasgow. Addiction 2009;104:308-16

75 Edwards R, McElduff $P$, Jenner $D$, et al. Smoking, smoking cessation, and use of smoking cessation aids and support services in South Derbyshire, England. Public Health 2007;121:321-32.

76 Lowey $H$, Tocque $K$, Bellis $M$, et al. Smoking cessation services are reducing inequalities. J Epidemiol Community Health 2003;57:579-80.

77 Hiscock R, Pearce J, Barnett R, et al. Do smoking cessation programmes influence geographical inequalities in health? An evaluation of the impact of the PEGS programme in Christchurch, New Zealand. Tob Control 2009;18:371-6.

78 Piper M, Cook J, Schlam T, et al. Gender, race, and education differences in abstinence rates among participants in two randomized smoking cessation trials. Nicotine Tob Res 2010;12:647-57.

79 Reitzel L, Mazas C, Cofta-Woerpel L, et al. Subjective social status affects smoking abstinence during acute withdrawal through affective mediators. Addiction 2010;105:928-36.

80 Biazzo L, Froshaug D, Harwell T, et al. Characteristics and abstinence outcomes among tobacco quitline enrollees using varenicline or nicotine replacement therapy. Nicotine Tob Res 2010;12:567-73.

81 Croghan I, Ebbert J, Hurt R, et al. Gender differences among smokers receiving interventions for tobacco dependence in a medical setting. Addict Behav 2009;34:61-7

82 Sadr AO, Lindström D, Adami J, et al. The efficacy of a smoking cessation programme in patients undergoing elective surgery: a randomised clinical trial. Anaesthesia 2009:64:259-65.

83 Gnich W, Sheehy C, Amos A, et al. A Scotland-wide pilot programme of smoking cessation services for young people: process and outcome evaluation. Addiction 2008; 103:1866-74.

84 Bryce A, Butler C, Gnich W, et al. CATCH: development of a home-based midwifery intervention to support young pregnant smokers to quit. Midwifery 2009:25:473-82.

85 McEwen A, Condliffe L, Gilbert A. Promoting engagement with a Stop Smoking Service via pro-active telephone calls. Patient Educ Couns 2010;80:277-9.

86 Okuyemi K, Thomas J, Hall S, et al. Smoking cessation in homeless populations: a pilot clinical trial. Nicotine Tob Res 2006:8:689-99.

87 Northridge $M$, Vallone $D$, Xiao $H$, et al. The importance of location for tobacco cessation: rural-urban disparities in quit success in underserved West Virginia counties. J Rural Health Res 2008:24:106-15.

88 Sias J, Urquidi U, Bristow Z, et al. Evaluation of smoking cessation behaviors and interventions among Latino smokers at low-income clinics in a US-Mexico border county. Addict Behav 2008;33:373-80.

89 King A, Sánchez-Johnsen L, Van Orman S, et al. A pilot community-based intensive smoking cessation intervention in African Americans: feasibility, acceptability and early outcome indicators. J Natl Med Assoc 2008;100:208-17.

90 Andrews J, Felton $\mathrm{G}$, Wewers $\mathrm{M}$, et al. The effect of a multi-component smoking cessation intervention in African American women residing in public housing. Res Nurs Health 2007;30:45-60.

91 Okuyemi $\mathrm{K}$, Zheng $\mathrm{H}$, Guo $\mathrm{H}$, et al. Predictors of adherence to nicotine gum and counseling among African-American light smokers. J Gen Intern Med 2010;25:969-76.

92 Okuyemi $\mathrm{K}$, James $\mathrm{A}$, Mayo $\mathrm{M}$, et al. Pathways to health: a cluster randomized trial of nicotine gum and motivational interviewing for smoking cessation in low-income housing. Health Educ Behav 2007:34:43-54.

93 Baker A, Richmond R, Haile M, et al. A randomized controlled trial of a smoking cessation intervention among people with a psychotic disorder. Am J Psychiatry 2006;163:1934-42.

94 Britton G, Brinthaupt J, Stehle J, et al. The effectiveness of a nurse-managed perinatal smoking cessation program implemented in a rural county. Nicotine Tob Res 2006;8:13-28.

95 Smith P, Burgess E. Smoking cessation initiated during hospital stay for patients with coronary artery disease: a randomized controlled trial. CMAJ 2009:180:1297-303.

96 Cupertino A, Mahnken J, Richter K, et al. Long-term engagement in smoking cessation counseling among rural smokers. J Health Care Poor Underserved 2007;18(4 Suppl):39-51.

97 Reitzel L, Vidrine J, Businelle $\mathrm{M}$, et al. Preventing postpartum smoking relapse among diverse low-income women: a randomized clinical trial. Nicotine Tob Res 2010:12:326-35. 
98 Sorensen G, Barbeau E, Stoddard A, et al. Tools for health: the efficacy of a tailored intervention targeted for construction laborers. Cancer Causes Control 2007:18:51-9.

99 Stewart M, Kushner K, Greaves L, et al. Impacts of a support intervention for low-income women who smoke. Soc Sci Med 2010;71:1901-9.

100 Burgess D, Fu S, Noorbaloochi S, et al. Employment, gender, and smoking cessation outcomes in low-income smokers using nicotine replacement therapy. Nicotine Tob Res 2009;11:1439-47.

101 Fernández E, Schiaffino A, Borrell C, et al. Social class, education, and smoking cessation: long-term follow-up of patients treated at a smoking cessation unit. Nicotine Tob Res 2006:8:29-36

102 An L, Schillo B, Kavanaugh A, et al. Increased reach and effectiveness of a statewide tobacco quitline after the addition of access to free nicotine replacement therapy. Tob Control 2006:15:286-93.

103 Maher J, Rohde K, Dent C, et al. Is a statewide tobacco quitline an appropriate service for specific populations? Tob Control 2007;16(Suppl 1):i65-70.

104 Tzelepis F, Paul C, Walsh $\mathrm{R}$, et al. Telephone recruitment into a randomized controlled trial of quitline support. Am J Prev Med 2009;37:324-9.

105 Murphy J, de Moreno S, Cummings K, et al. Changes in cigarette smoking, purchase patterns, and cessation-related behaviors among low-income smokers in New York State from 2002 to 2005. J Public Health Manag Pract 2010;16:277-84

106 Miller C, Sedivy V. Using a quitline plus low-cost nicotine replacement therapy to help disadvantaged smokers to quit. Tob Control 2009;18:144-9.

107 Strecher V, McClure J, Alexander G, et al. The role of engagement in a tailored web-based smoking cessation program: randomized controlled trial. J Med Internet Res 2008;10:e36.

108 An L, Schillo B, Saul J, et al. Utilization of smoking cessation informational, interactive, and online community resources as predictors of abstinence: cohort study. J Med Internet Res 2008;10:e55.

109 Seidman D, Westmaas J, Goldband S, et al. Randomized controlled trial of an interactive internet smoking cessation program with long-term follow-up. Ann Behav Med 2010;39:48-60.

110 Bao Y, Duan N, Fox S. Is some provider advice on smoking cessation better than no advice? An instrumental variable analysis of the 2001 National Health Interview Survey. Health Serv Res 2006:41:2114-35.
111 Crittenden K, Manfredi C, Cho Y, et al. Smoking cessation processes in low-SES women: the impact of time-varying pregnancy status, health care messages, stress, and health concerns. Addict Behav 2007:32:1347-66.

112 Turner L, Mermelstein R, Hitsman B, et al. Social support as a moderator of the relationship between recent history of depression and smoking cessation among lower-educated women. Nicotine Tob Res 2008;10:201-12.

113 Velicer W, Redding C, Sun X, et al. Demographic variables, smoking variables, and outcome across five studies. Health Psychol 2007;26:278-87.

114 Reid R, Pipe A, Quinlan B, et al. Interactive voice response telephony to promote smoking cessation in patients with heart disease: a pilot study. Patient Educ Couns 2007;66:319-26.

115 NICE. Brief interventions and referral for smoking cessation in primary care and other settings. London: National Institute for Health and Care Excellence, 2006.

116 Wendel-Vos G, Dutman A, Verschuren W, et al. Lifestyle factors of a five-year community-intervention program. Am J Prev Med 2009;37:50-6.

117 Kloek G, van Lenthe F, van Nierop $P$, et al. Impact evaluation of a Dutch community intervention to improve health-related behaviour in deprived neighbourhoods. Health Place 2006;12:665-77.

118 Ellis JA, Perl SB, Davis K, et al. Gender differences in smoking and cessation behaviors among young adults after implementation of local comprehensive tobacco control. Am J Public Health 2006:98:310-16.

119 Macintyre S. Evidence based policy making. BMJ 2003;326:5-6.

120 Kohatsu N, Robinson J, Torner J. Evidence-based public health: an evolving concept. Am J Prev Med 2004;27:417-21.

121 Macintyre S. Good intentions and received wisdom are not good enough: the need for controlled trials in public health. J Epidemiol Community Health 2011;65:564-7.

122 Hornik RC. Public health communication: evidence for behavior change. 2nd edn. Mahwah, NJ: Laurence Erlbaum Associates, 2008.

123 Graham H. Unequal lives: health and socio-economic inequalities. Maidenhead: McGraw-Hill Open University Press, 2007.

124 Whitehead M, Petticrew M, Graham H, et al. Evidence for public health policy on inequalities: 2: assembling the evidence jigsaw. J Epidemiol Community Health 2004;58:817-21

125 Akhtar $\mathrm{P}$, Haw S, Levin K, et al. Socioeconomic differences in second-hand smoke exposure among children in Scotland after introduction of the smoke-free legislation. J Epidemiol Community Health 2010;64:341-6. 